\title{
Association of Educational Planning with Mental Health of Nursing Students of Tehran Medical Science University with Emphasis on the Educational Stressor Factors and Stress Management Methods
}

\begin{abstract}
Background and objective: Inappropriate function of organizations is directly associated with the physical and psychological health of the society. One such organizations are medical universities which are responsible for educating students of nursing. This study focuses on the association of educational planning with the mental health of nursing students of Tehran Medical Science University with emphasis on the educational stressor factors and stress management methods.

Materials and methods: In this descriptive-cross sectional two questionnaires were used: researcher-made questionnaire $(a=0.71)$ and Jalowiec Coping Styles Questionnaire. The correlation coefficient of test and retest after 3 weeks was used for Jalowiec questionnaire $(r=0.89)$. The random sampling method among nursing students of Tehran University Medical science was used and the size of the sample was 376. Data were analyzed using descriptive statistics and analytical ones (t-test and ANOVA) through SPSS 21.

Results: Out of 354 students, $32.1 \%$ were suspected to have psychological disorders. These disorders were $29.7 \%$ among females and $34.6 \%$ among males, respectively. There was a statistical correlation between mental health and previous physical illnesses $(p<0 / 05)$. There was a significant correlation between stressful factors experienced and mental health. In addition, there was a significant correlation between mental health and educational stressful factors such as negative attitudes in the community about nursing and ambiguity about professional role of nurses at the time of education $(p<0.05)$.

Conclusion: A number of nursing students were suspicious to have mental disorders. Therefore, in order to prevent physical and psychological destructive effects of stress on students, it is recommended to think about the educational stressful factors to diminish mental problems.

Paper Type: Research Article.

Keywords: Educational planning, Nursing students, Educational stressor factors, Mental health, Stress management, Tehran University of Medical Sciences (TUMS), Tehran.

Citation:Abdollahi D. Association of Educational Planning with Mental Health of Nursing Students of Tehran Medical Science University with Emphasis on the Educational Stressor Factors and Stress Management Methods. Iran J Health Educ Health Promot. Spring 2016;4(1): 40-49.
\end{abstract}

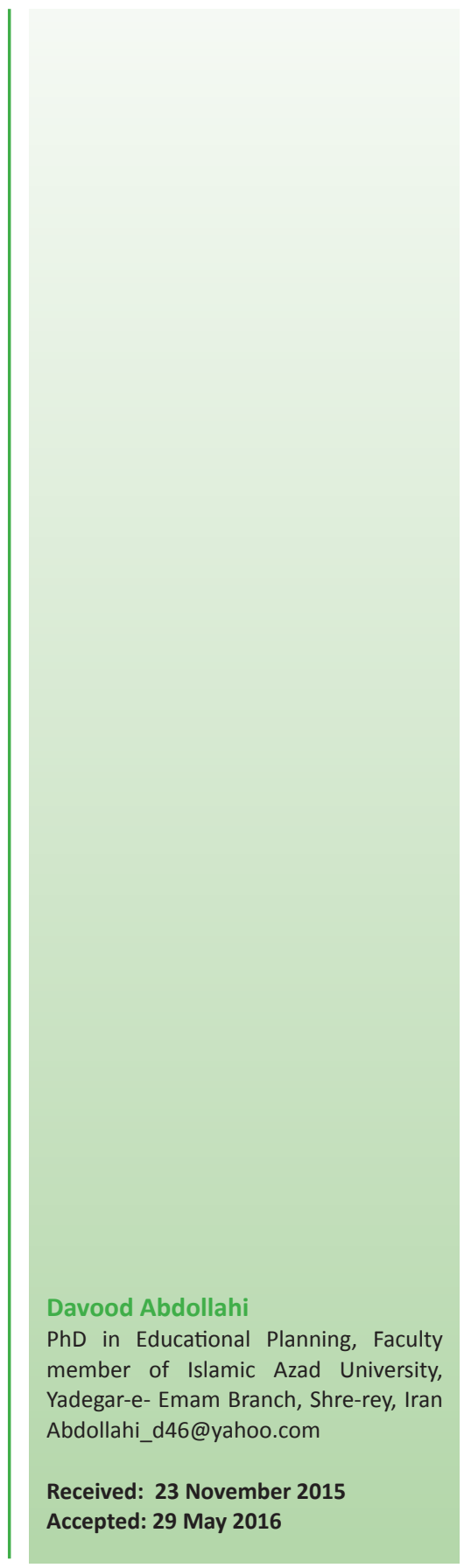




\section{ارتباط برنامهريزى آموزشى با بهداشت روانى دانشجويان يرستارى دانشعاه علوم يزشكى تهران با تأكيد بر عوامل استرسزاى آموزشى و روشهاى مديريت استرس}

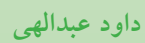
دكتراى برنامهريزى آموزشى، عضو هيئتعلمى،مربى،

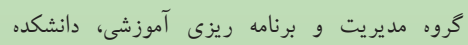

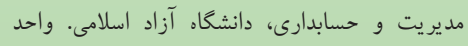
ياد كار امام، شهررى، ايران Abdollahi_d46@yahoo.com

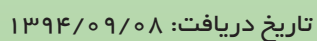

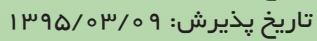

\section{or}

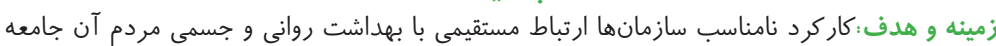

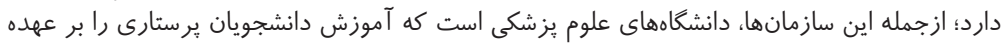

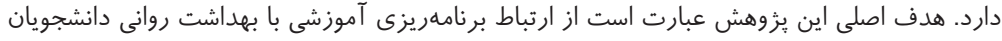

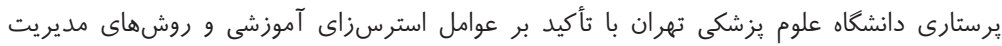
استرس.

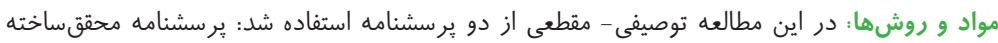

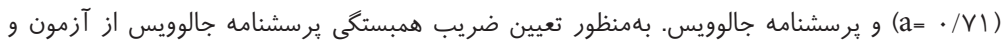

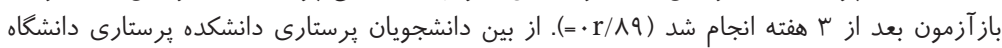

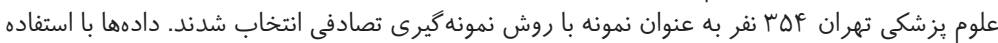

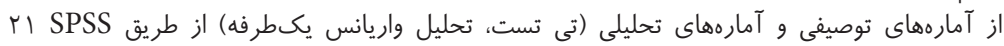

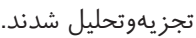

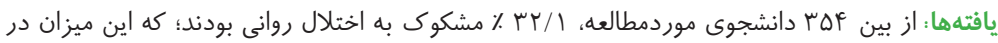

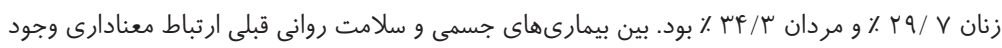

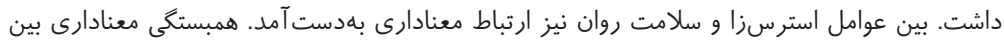

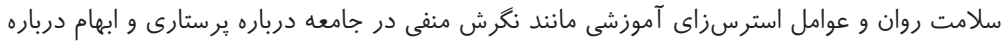

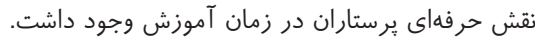

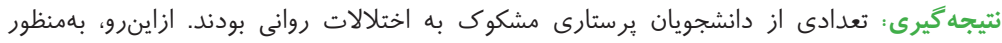

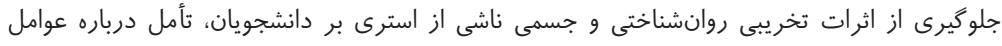

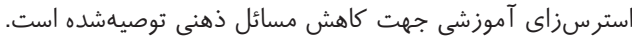

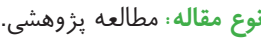

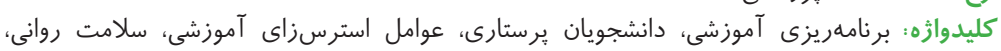

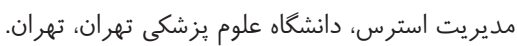

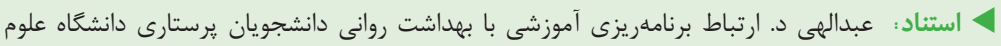

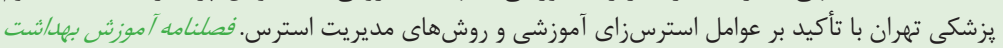

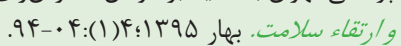


كزارش دالين و همكاران (F) ميانكين استرس دانشجويان

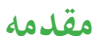

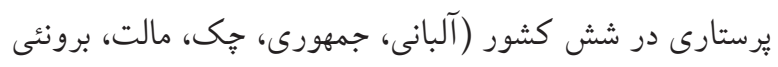

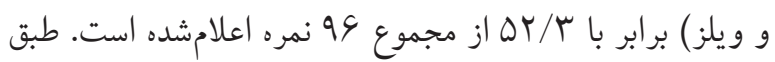

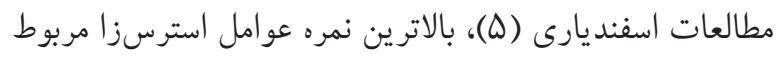
به دانشجويان يرستارى است؛ بهطورى كه اين دسته از دانشجويان هم استرس بيشترى را تجربه مى كنند و هم ازنظر سلامت روانى

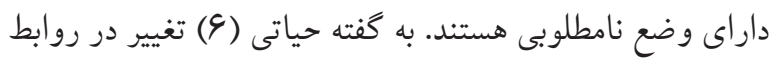

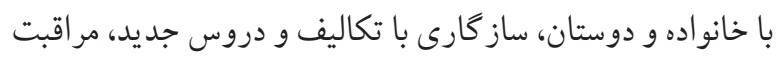

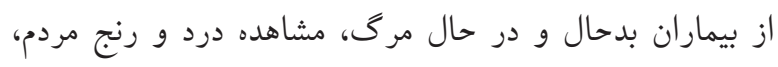

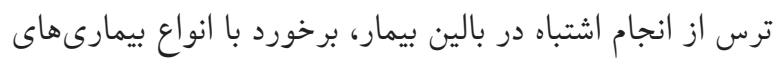

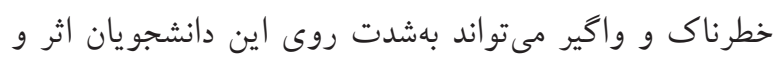

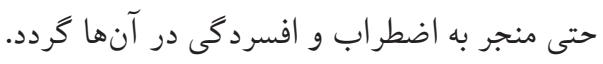

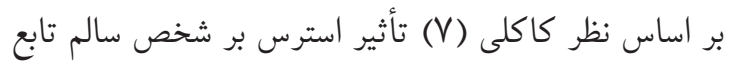

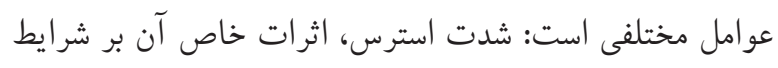
زندكى، وضعيت جسمى و روانى فرد. صادقيان و همكاران () (مر مطالعهاى كه بر روى سلامت روانى دانشجويان علوم

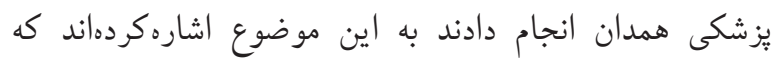

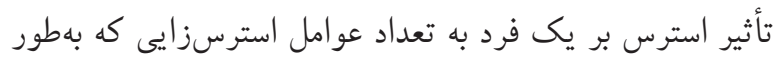

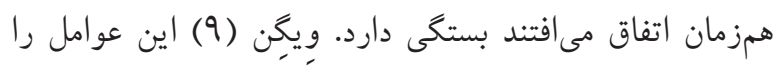

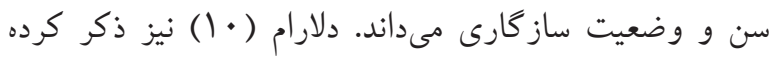

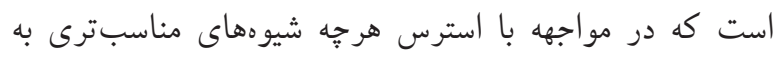

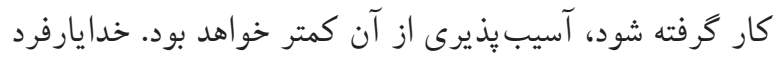

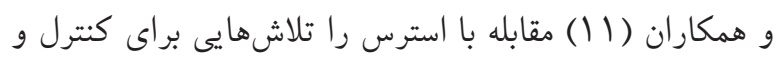

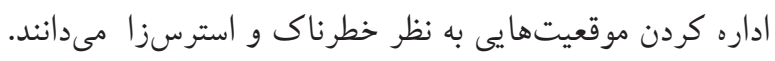

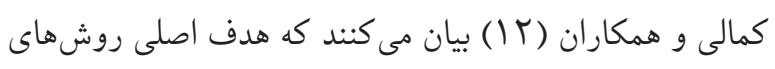

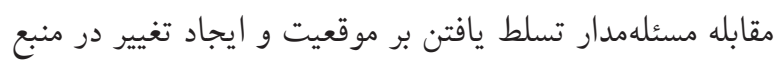
استرسزا است، و هدف اصلى روشهاى مقابله هيجانمدار كاهش يا تبديل سريع آشفتكى هيجانى است.

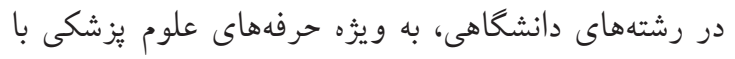
جان انسانها سروكار دارند. به علت تعامل مستقيم دانشجويان

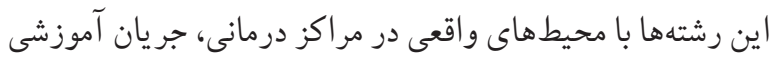

منظور از آموزش، فراهم نمودن محيطى است كه موجبات تسهيل يادكيرى شود (1). رسالت سازمانهاى آموزشى، برورش (رشد آند

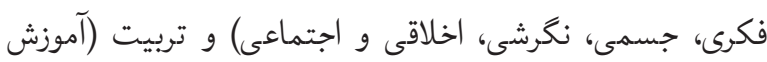

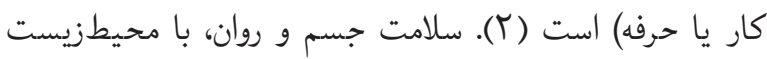

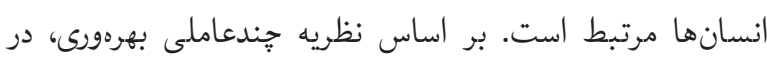

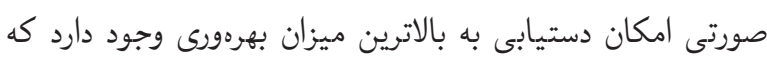

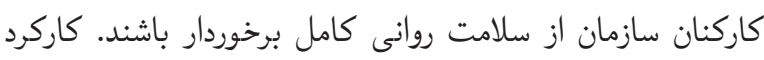

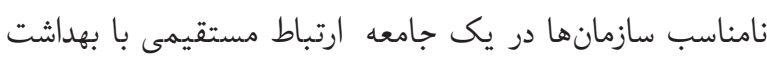

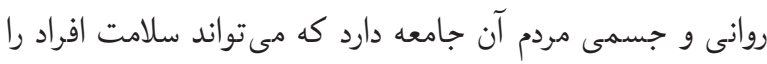
در معرض خطر قرار مى دهد. ازجمله اين سازمانها، دانشكاههاى علوم يزشكى است كه آموزش دانشجويان يرستارى از كاركردهاى آنساي

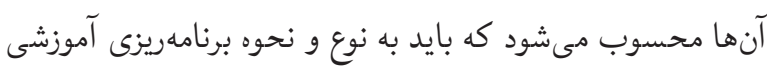
و درسى آن توجه خاص شود. يرّوهش حاضر از اين نظر حائز اهميت است كه به بردسى

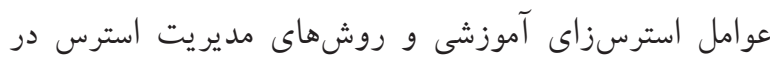

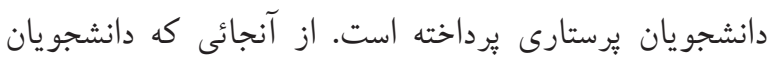

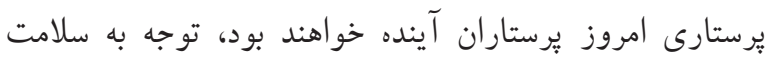

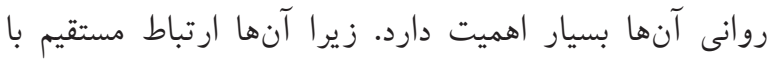

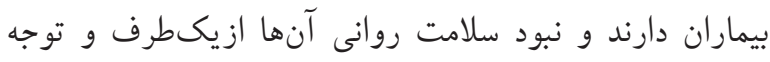
نداشتن به عوامل استرسزاى محيطى، كه نحوه آموزش يكى از از

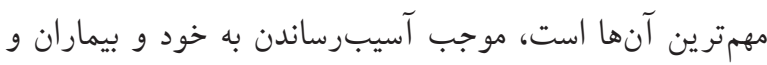
اطرافيان خواهد شد. بنا بر تحقيقات انجمن ملى بهداشت روانى، بردئ

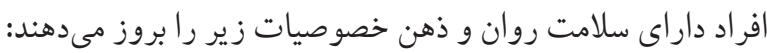
I- ازنظر روانى و ذهنى احساس راحتى مى كنند؛ ب- احساس

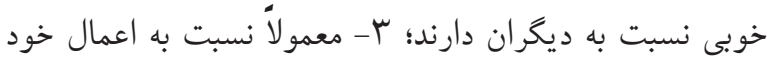

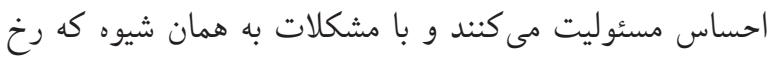

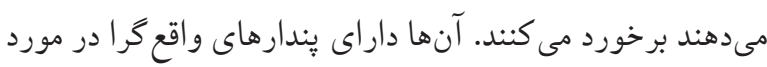

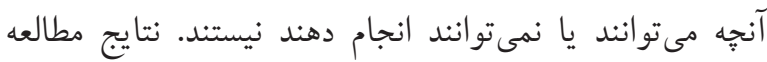

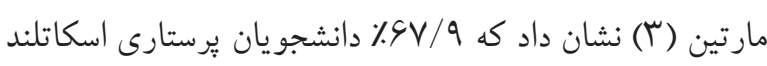

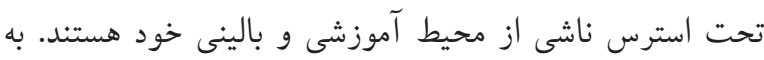


بر روند معمول زندكى، رفتار و عملكرد فرد تأثير منفى داشته،

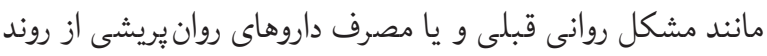
يُوهش خارج شدند. در كل مل ماند دانشجو به روش تمامشمارى در مطالعه شركت داده شدند.

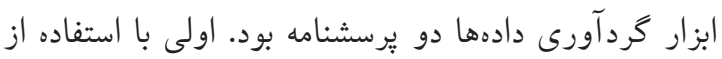
منابع علمى و با توجه به اهداف يزوهش در دو بخش تنظيمشده

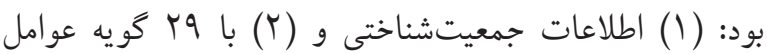
استرسآور بهصورت گروهبندى شده. عوامل استرس آور مشتمل بر جهار حيطه بودند: ارتباط بين فردى (^ گويه)، كارهاى بالينى

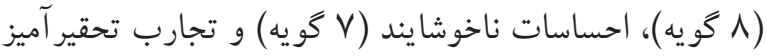
(4 كويه). ميزان استرس آور بودن هر كدام با عبار ات بههيجوجه،

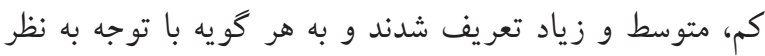

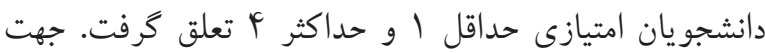

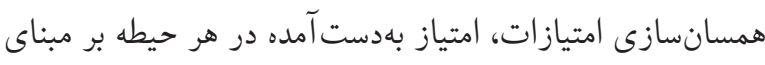

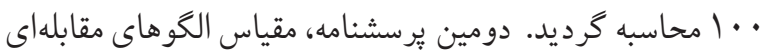

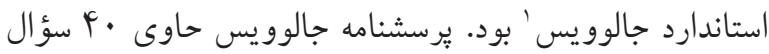
ينج گزينهاى با مقياس ليكرت است. به دليل اينكه يكى از

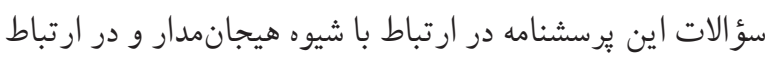

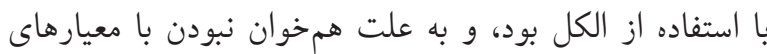

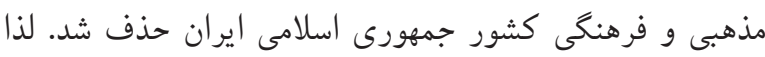

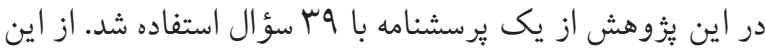

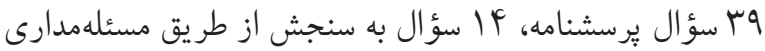
و هو سؤال به سنجش از طريق هيجانمدارى اختصاص يافتند.

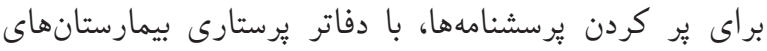

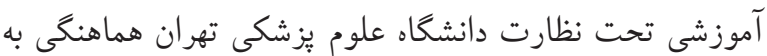

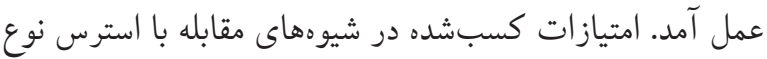

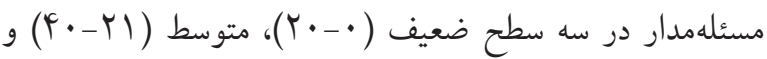

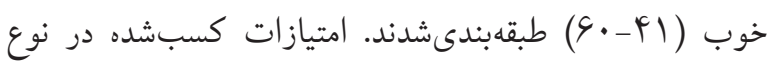

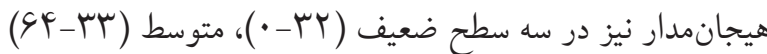
و خوب (9 (90) طبقهبندى شدند. براى تجزيهوتحليل دادهها

1. Jalowiec Coping Styles Questionnaire
آنها با استرس و بر هم خوردن سلامت روانى آنها همراه است

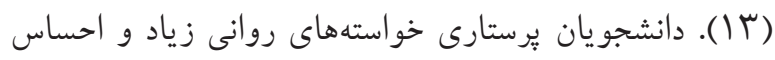

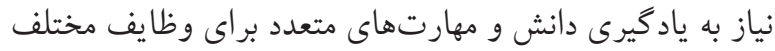

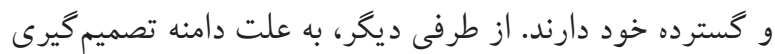

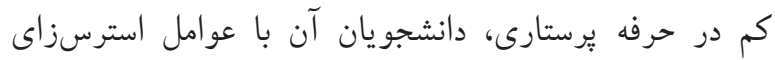

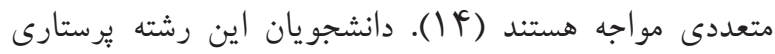

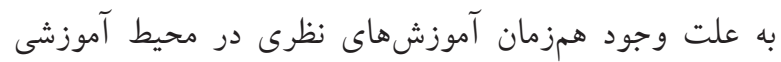

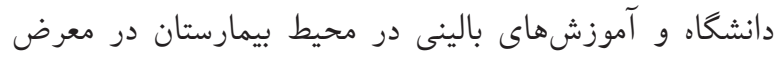
هر دو منبع استرسزا قرار مى گيرند (ه) (1). اثر استرس دارئى دو قطب مثبت و منفى است. جنانجه دانشجويان يُرستارى اين

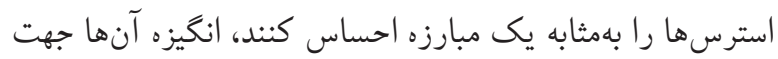
يادكيرى افزايش مى يابد (9)). اما جنانجه ميزان استرس زياد و و تهديدكننده باشد، مىتواند باعث افت تحصيلى و مانع از ظهور

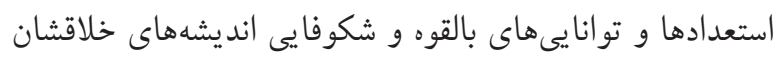

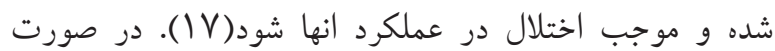
توجه و اعتقاد نداشتن به سلامت روانى كار كنان مراكز درمانى، نمىتوان انتظار داشت آن سازمانها خدمات خوبى به بيماران

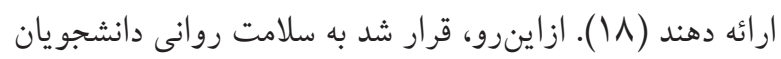

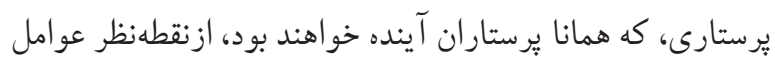

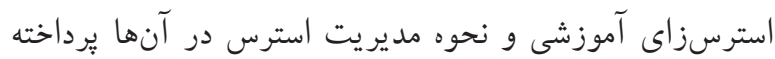

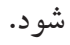
مو اد و روشها اين مطالعه توصيفى- تحليلى از نوع مقطعى در سال ؤوسا در دانشكده پِرستارى دانشكاه علوم يزشكى تهران بر روى دانشجويان يرستارى انجام كرفت. در اين مطالعه دانشجويان يرستارى با بران

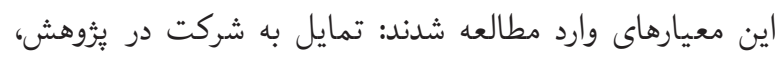

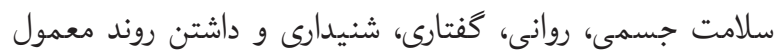

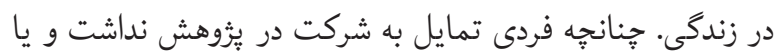
در روند زندكى معمول خود، واقعه استرس زايى مانند فوت عزيزان، بيمارى صعبالعلاج براى خود يا خانواده و هر واقعه ديكر كه 
حقوقبخيرى بود. از عوامل استرسزاى مربوط به ((ارتباطات بين فردى))،

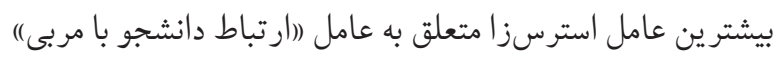

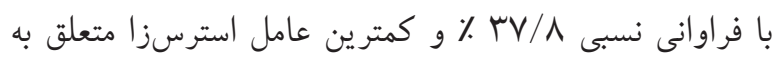

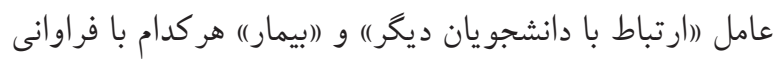
نسبى ^/ • ٪ بود. از عوامل استرسزاى مربوط به (افعاليتهاى

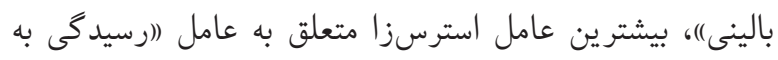

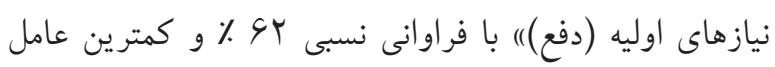

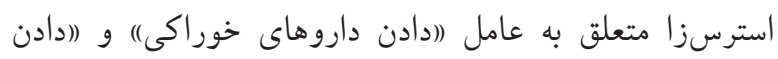

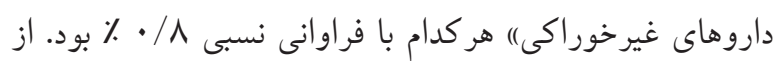

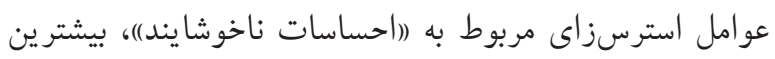

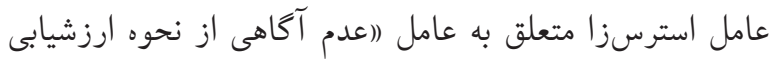

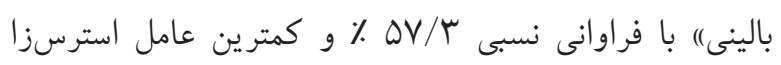

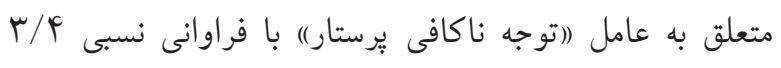
\% بود. از عوامل استرسزاى مربوط به ((تجربيات تحقير آميز)) بيشتر ين عامل استرسزا متعلق به عامل ((تعويض ملحفه بيمار))

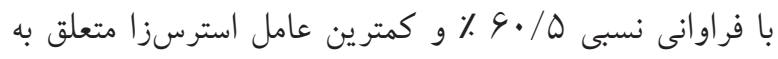
عامل (اگلايه كردن بيماران و همراهان در مورد رفتار نامناسب لهب

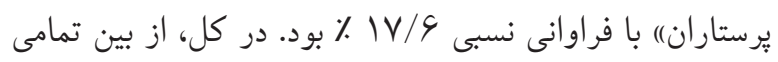

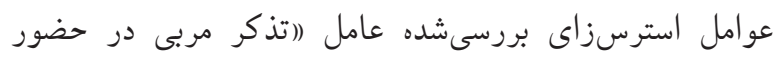

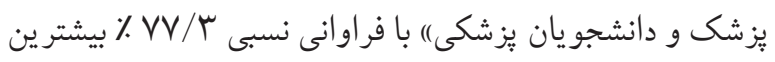
ميزان استرس و عامل (ابرقرارى ارتباط دانشجوى يُرستارى با بـان

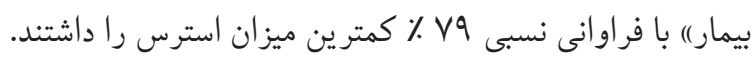
بين محل سكونت، وضعيت تأهل و دوره تحصيلى دانشجويان

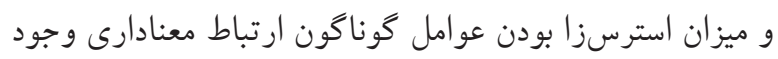
نداشت. بررسى ارتباط بين نيمسالهاى تحصيلى و جهار حيطه

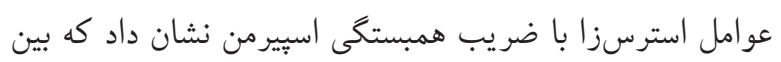

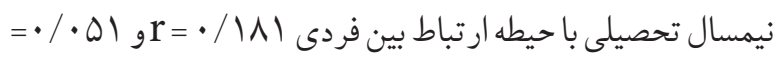

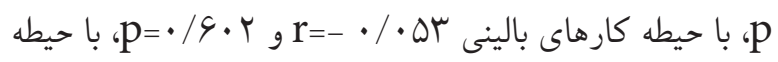

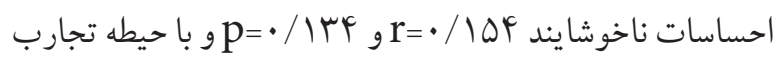

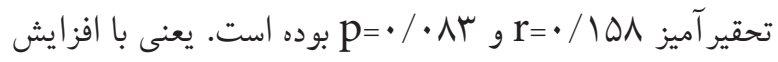

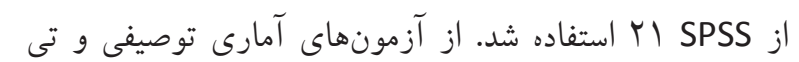
تست (براى بررسى ارتباط ميانكين نمرات با جنس، محل تولد، وضعيت تأهل، مقطع تحصيلى و زندهبودن والدين) و نيز تحليل برديل واريانس يكىطرفه (براى تعيين ارتباط ميانخين نمرات با سن) | استفاده شد. سطح معنادارى در نظر كرفتهشده ه / • بود. براى تعيين روايى محتوايى يرسشنامه ازنظر متخصصان و

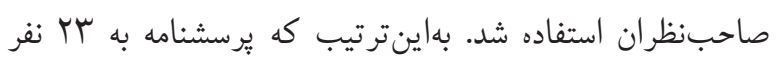

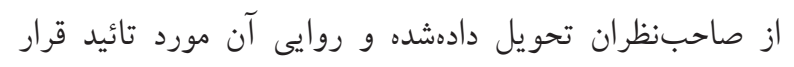

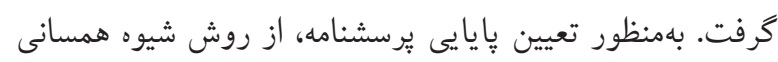

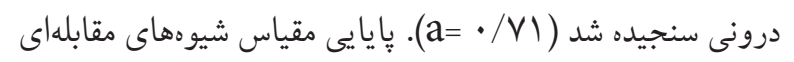

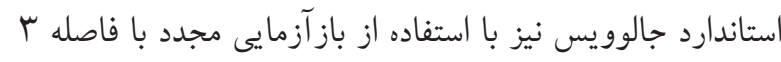

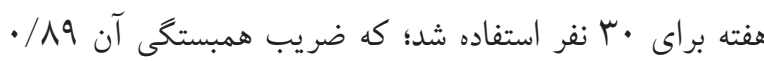
بود. براى تجزيهو تحليل آمارى، از آمار توصيفى (درصد، ميانكين، انحراف معيار) براى تعيين استرسزا بودن هر عامل استفاده شد.

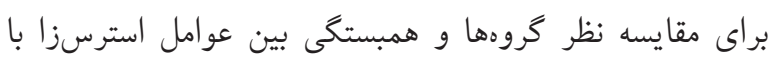

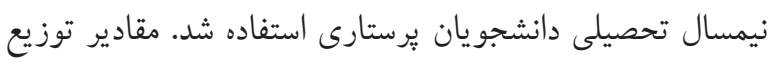

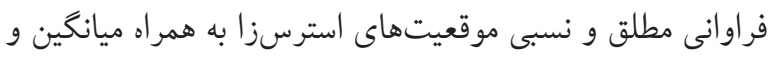
انحر اف استاندارد در جدول إنشان دادهده است.

يافتهه ها

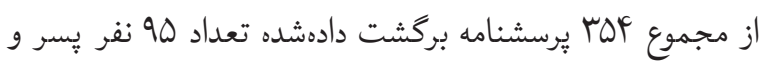

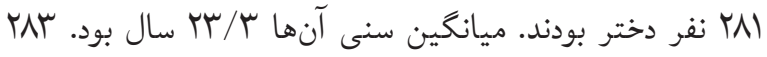
نفر مجرد و ل V نفر متأهل بودند.

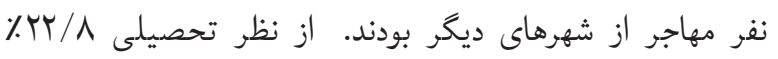
دانشجويان در نيمسال تحصيلى سوم، 19/9 ٪ در نيمسال تحصيلى جهارم، 10/1 ٪ در نيمسال تحصيلى ينجم، در نيمسال تحصيلى ششم، 19/9 ٪ در نيمسال تحصيلى هفتم و ا 10/\% در نيمسال تحصيلى هشتم مشغول به تحصيل بودند.

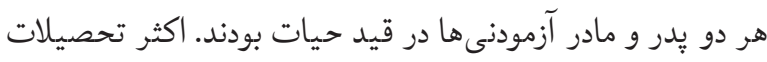

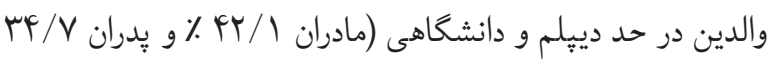

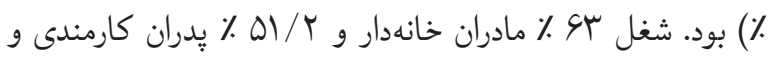


جدول ا. توزيع فراوانى و فراوانى نسبى موقعيتهاى استرسزا به همراه ميانگين و انحراف استاندارد

\begin{tabular}{|c|c|c|c|c|c|c|c|c|c|c|c|}
\hline \multirow{3}{*}{$\begin{array}{c}\text { استاندارد } \\
\text { r/AV }\end{array}$} & \multirow{3}{*}{ ميانگين } & \multicolumn{2}{|c|}{ هر كز (1) } & \multicolumn{2}{|c|}{ كم (r) } & \multicolumn{2}{|c|}{ متوسط (Y) } & \multicolumn{2}{|c|}{ زياد (F) } & \multirow{2}{*}{\multicolumn{2}{|c|}{$\begin{array}{l}\text { موقعيتهاى استرسزا } \\
\text { rof }\end{array}$}} \\
\hline & & \multirow{2}{*}{ درصد } & \multirow{2}{*}{ تع ت } & \multirow{2}{*}{ د درصد } & \multirow{2}{*}{ تعداد } & \multirow{2}{*}{ درصد } & \multirow{2}{*}{ تعداد } & \multirow{2}{*}{ درب } & \multirow{2}{*}{ تعداد } & & \\
\hline & & & & & & & & & & ل يزشى & \multirow{8}{*}{ 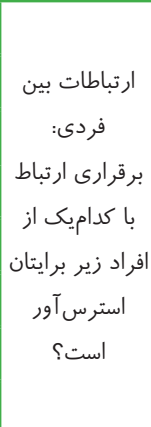 } \\
\hline l/^r & $\cdot / \mathrm{VA}$ & $1 / V$ & $\varepsilon$ & $1 V / 4$ & s r & fr & 10 & $\mathrm{r} \vee / \Lambda$ & iro & 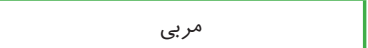 & \\
\hline $1 / 9 \wedge$ & $\cdot / \wedge \vee$ & $\Delta r / \Lambda$ & 194 & $r V / V$ & 99 & $\mid r / f$ & iᄉ & $r / r$ & 10 & سويروايزر & \\
\hline$r / \cdot r$ &.$/ 91$ & $r \vee / \Lambda$ & $1 \mu \Delta$ & $r q / 4$ & $1 \cdot 0$ & $r \mu / \Delta$ & $\wedge r$ & $\Lambda / f$ & r. & سريرستار & \\
\hline $\mid / 91$ & $\cdot / V^{r}$ & $\Delta r / 1$ & $1 \wedge 9$ & $\Delta \mu / \mu$ & Irs & $1 \cdot / 1$ & re & $1 / V$ & 4 & يرستاران بخش & \\
\hline $1 / 8 \Lambda$ & $\cdot / V^{F}$ & $r \varepsilon / F$ & 190 & $r V / q$ & Irr & $1 \mu / r$ & is & $r / l$ & 9 & ملاقاتىها & \\
\hline 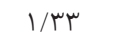 &.$/ 9 \mu$ & $V r / q$ & TFF & $1 N / 0$ & s4 & $\Delta / 9$ & r & $\cdot / \Lambda$ & r & دانشجويان & \\
\hline $1 / r \Delta$ & $\cdot / \Delta \Delta$ & v9 & rAY & 19 & $\Delta V$ & $r / \uparrow$ & ir & $\cdot / \Lambda$ & r & 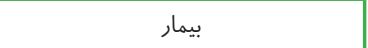 & \\
\hline$f F / \varepsilon r$ & $I r / F V$ & & & & & & & & & & كل \\
\hline$r / 09$ & $1 / \cdot r$ & $19 / 1$ & 4. & $r q / p$ & 190 & $\mu \cdot / \mu$ & $19 \Lambda$ & $r Y / V$ & $\wedge 1$ & مراقبت از بيماران بدحال & \\
\hline 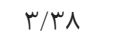 & .199 & $r / \Lambda$ & r. & $F / \Lambda$ & r. & $19 / \pi$ & 99 & r & rTo & رسيدگى به نيازهاى اوليه (دفع) & \\
\hline r/ş &.$/ 99$ & 19 & $\Delta V$ & $r \cdot / r$ & Vr & $F F / \Delta$ & 109 & $1 N / 0$ & s4 & مراقبت از بيمار & 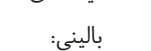 \\
\hline $1 / 9 \wedge$ & $\cdot / \wedge \varsigma$ & $\Delta r / q$ & 119 & $\mu 1 / 1$ & 111 & $1 \cdot / 9$ & rq & $\Delta$ & 11 & مراقبت از بيماران غير همجنس & انجام كداميك \\
\hline $1 / V F$ & $\cdot / V^{c}$ & Fr/q & lor & $F \mid / r$ & IFV & $10 / 1$ & $\Delta F$ & $\cdot / \Lambda$ & r & دادن داروهاى خوراكى & از كارهاى بالينى \\
\hline$r / \cdot 9$ & $\cdot / \Lambda$ & $r \mu / \Delta$ & $\wedge F$ & $p V / q$ & $|V|$ & $Y F / F$ & $\Delta V$ & $r / r$ & 10 & ديدن زخم و انجام پانسمان & براى شما ايجاد \\
\hline$r / 11$ &.$/ 94$ & $r \cdot / \mu$ & $1 \cdot \wedge$ & $r s / 1$ & $1 r 9$ & $r \& / 1$ & $9 \pi$ & $V / 4$ & rV & ديدن جسد & \\
\hline $1 / r \Delta$ & $\cdot / \Delta r$ & $V N / r$ & rVq & $1 N / \Delta$ & 49 & $1 / V$ & 4 & $\cdot / \Lambda$ & r & دادن داروهاى غيرخوراكى & \\
\hline$\Delta F / \subseteq q$ & $11 / r 9$ & & & & & & & & & & كل \\
\hline r/Ar & $\cdot / \wedge 9$ & $\Delta / 9$ & rl & $r q / 4$ & $1 \cdot 0$ & $\varphi \cdot / \mu$ & IfF & $r \mu / Q$ & $\wedge F$ & كشمكش با بيمار يا همر اهان او & احساسات \\
\hline T/ & $\cdot / \Lambda F$ & 19 & $\Delta V$ & $r q / \Delta$ & $|f|$ & $r s / 1$ & $1 r 9$ & $V / \varsigma$ & rV & ترس از واگيرى بيمارى عفونى & 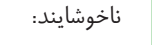 \\
\hline$r / 41$ & $\cdot / V^{F}$ & $1 / V$ & 4 & $1 \cdot / 1$ & rs & $r \mu / 4$ & ir. & $\Delta r / \Lambda$ & $19 r$ & رنج كشيدن بيمار & كداميك \\
\hline$r / \mu q$ & ./AT & $r / r$ & 10 & $\Lambda / F$ & r. & $r y / 1$ & 111 & $\Delta V / \mu$ & $r \cdot 1$ & عدم آكًاهى از نحوه ارزشيابى بالينى & كدام كو از اين \\
\hline 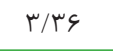 & $\cdot / V 4$ & $r / \Delta$ & 9 & $9 / \pi$ & r & $\mathrm{rV} / \mathrm{\Lambda}$ & $1 \mu \Delta$ & $\Delta \cdot / f$ & 11 & عدم درمان كافى به علت نداشتن يول & موارد، استرس \\
\hline r/ץ & $\cdot / V S$ & $r / \Delta$ & 9 & $9 / r$ & r & $r s / 1$ & 119 & $\Delta r / l$ & $1 \wedge 9$ & توجه ناكافى بزشك & بيشترى به شما \\
\hline $1 / 9$ & $\cdot / \Lambda r$ & $r \Delta / \mu$ & Irs & er & 10 & $1 N / \Delta$ & 49 & $r / \uparrow$ & ir & توجه ناكافى يرستار & وارد مى كند؟ \\
\hline$V T / S F$ & $1 r / 94$ & & & & & & & & & & كل \\
\hline$r / v$. & $V V / r$ & $1 / V$ & \& & $\Delta$ & 11 & $10 / 1$ & is & $V V / r$ & rVS & تذكر مربى در حضور يزشك و دانشجويان & \\
\hline$r / S V$ & $1 / 11$ & $1 N / 0$ & 49 & $r s / 9$ & 99 & $r l / \Lambda$ & VA & $r 1 / 9$ & $11 F$ & مرتب كردن وسايل بيمار & \\
\hline$r / 41$ & $\cdot / \wedge \varsigma$ & $r / r$ & 10 & $1 N / 1$ & fr & $r l / \Lambda$ & VA & $9 \cdot 10$ & ris & تعويض ملحفه بيمار & \\
\hline$r / V V$ & $1 / 11$ & $19 / 1$ & 4. & $r F / F$ & $\wedge \vee$ & $r T / V$ & $\wedge 1$ & $r \Delta / \mu$ & Irs & تذكر مربى در حضور ساير دانشجويان & تجقير آميز \\
\hline$r / \mu V$ & $1 / .9$ & $r \varepsilon / 9$ & 94 & $r s / 9$ & rf & YN/S & $1 \cdot r$ & $1 V / 9$ & $s \mu$ & كلايه كردن بيماران و همراهان در مورد & \\
\hline$r / V V$ &.$/ 99$ & $1 \cdot / 9$ & rq & $\mu \cdot / \mu$ & $1 \cdot 1$ & $r q / 4$ & $1 \cdot 0$ & $r q / r$ & $1 \cdot 0$ & بلند صدازدن نام دانشجو توسط كار كنان & \\
\hline$V r / V I$ & $1 F / 09$ & & & & & & & & & & كل \\
\hline
\end{tabular}


فراوانى مطلق و نسبى، انحراف معيار و ميانكين بهدستآمد. جدول Y اين مقادير را نشان مىدهد. ميانگين نمر ات در ارتباط با فيا

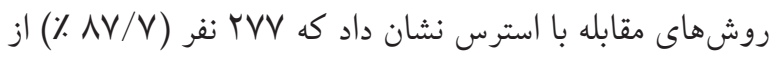

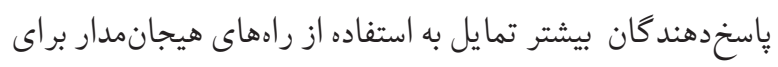

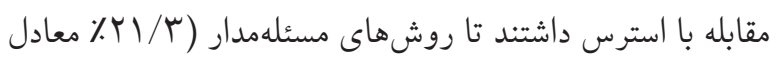

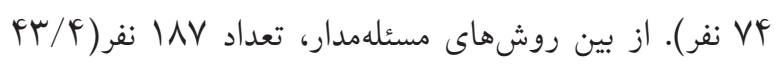

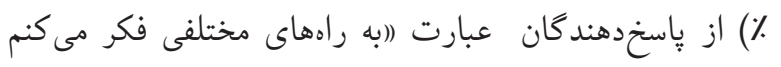
تا بتوانم وضعيت خود را بهتر كنم) را مدنظر داشتند. و همحجنين

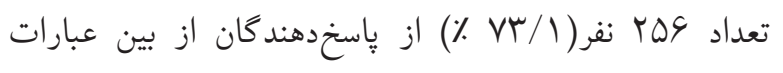
مربوط به راهحلهاى هيجانمدار عبارت (ادعا مى كنم و به خدا

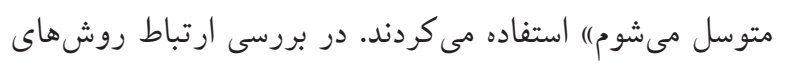
مختلف مقابله با استرس و ويزگى مهاى شخصى، ميانگين نمره

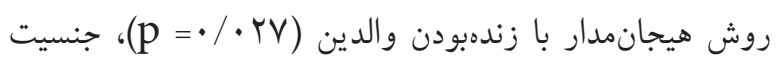

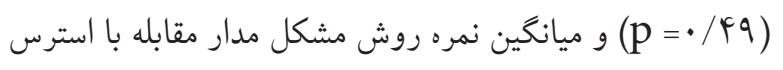

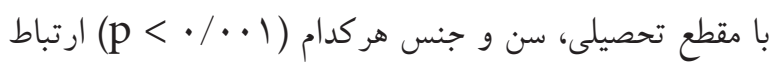
معنادارى داشتند.
نيمسال تحصيلى، ميزان استرس ناشى از عوامل سه حيطه ديكر

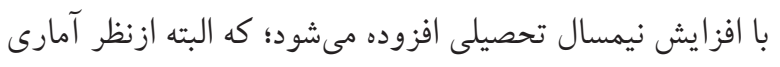
رابطه معنادارى محسوب نمىشود. مجموع نمراتى كه دانشجويان

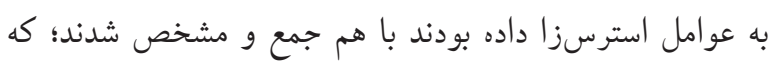

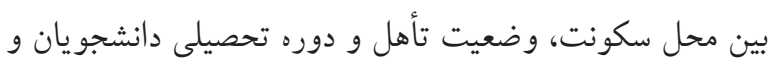

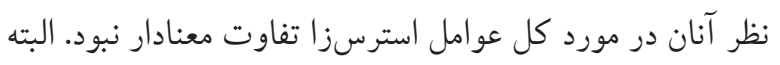
بين دانشجو يان نيمسالهاى تحصيلى مختلف، اين تفاوت معنادار

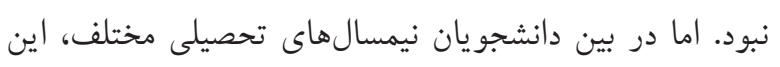

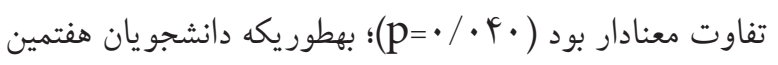

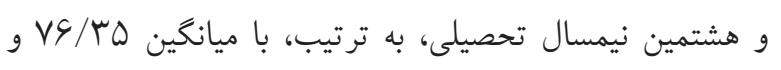

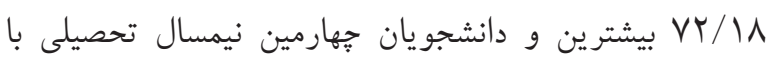

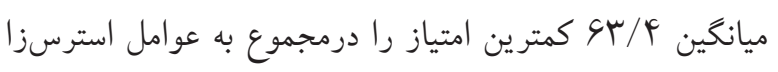
دادند. يعنى دانشجو يانى كه در نيمسالهاى تحصيلى بالاتر بودند، استرس بيشترى را در محيطهاى بالينى تجربه كردند.

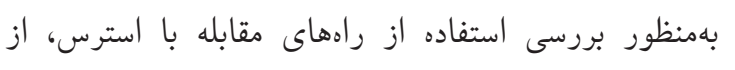

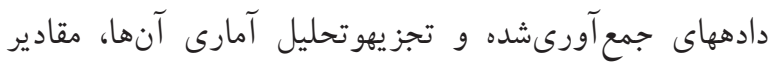

جدول r. فراوانى، فراوانى نسبى، ميانكَين و انحراف استاندارد استفاده از روشهاى مقابله با استرس در دانشجويان

\begin{tabular}{|c|c|c|c|c|c|c|c|c|c|c|}
\hline \multirow{2}{*}{ ميانگين } & \multirow{2}{*}{ معيار } & \multicolumn{2}{|c|}{ جمع } & \multicolumn{2}{|c|}{ اغلب و هميشه } & \multicolumn{2}{|c|}{ كاهى } & \multicolumn{2}{|c|}{ هر كز و خيلى كم } & \multirow{2}{*}{ استفاده از روشهاى مقابله با استرس } \\
\hline & & درصد & تعداد & درصد & تعداد & درصد & تعداد & درصد & تعداد & \\
\hline $8 / 11$ & rl/rq & $1 \cdots$ & rol & $r \mid r$ & $V^{F}$ & $V \Delta / \mathcal{F}$ & $r \$ 0$ & 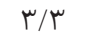 & 11 & شيوههاى مسئلهمدار \\
\hline $9 / 4 r$ & $F V / 11$ & $1 \cdots$ & MV & $\Lambda V / \mathcal{F}$ & rVV & $1 r / 9$ & rq & . & . & شيوههاى هيجانمدار \\
\hline
\end{tabular}

يُزوهش نيز مشكلاتى را از سوى مربيان خود احساس مى كردند. بִ

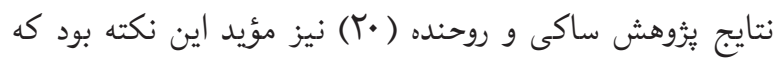
هتك حرمتِ مربى به دانشجو در حضور سايرين و وجود ارتباط

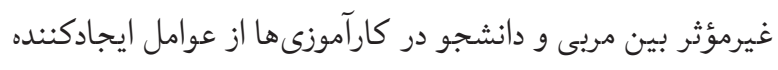

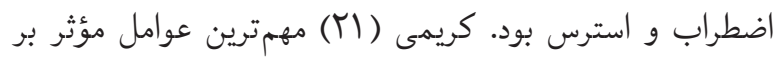
اضطراب دانشجويان را به ترتيب محيط بالينى و مربى دانست.

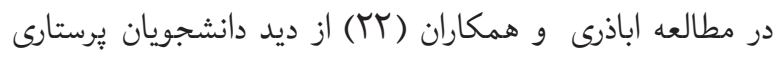
در شهر كرمان نيز ارتباط برقرار كردن با مربيان برستارى ازجمله

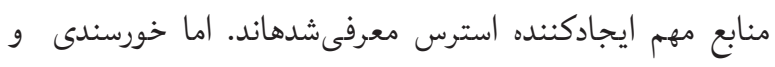

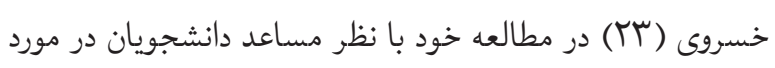

شروع به تحصيل در دانشخاه با تغييرات عمدهاى در روابط اجتماعى، انتظارات و نقشها همراه است؛ كه دانشجويان را مستعد اختلالات

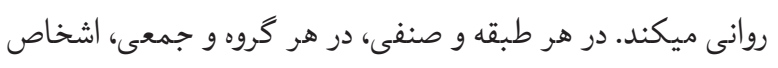

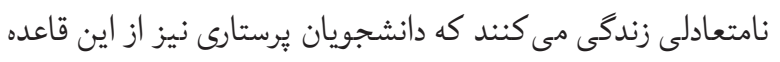

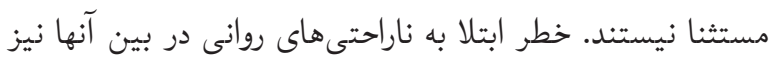

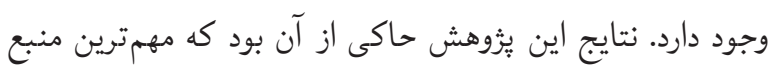
استرسزا در دانشجويان موردبررسى (اتذكر مربى در برقرارى ارتباط

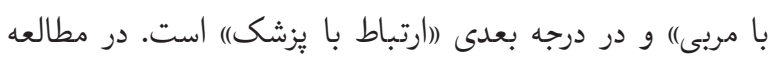

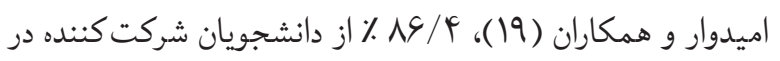


استر اليا صورت كرفت، مشخص شد كه دانشجو يان در سال اول به نسبت ساير سالهاى تحصيلى استرس كمترى را تجربه مى كنند.

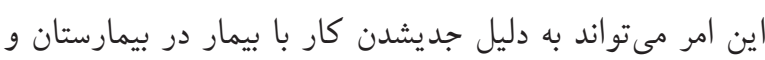

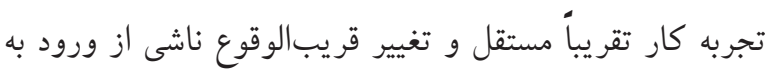

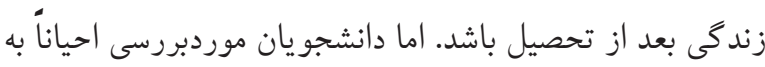

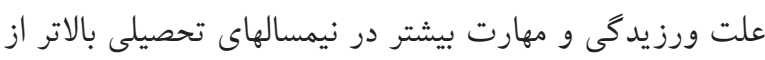
استرس كمترى برخوردار بودند. بهطور كلى، در اين مطالعه در بررسى منابع استرس همانتد بردس

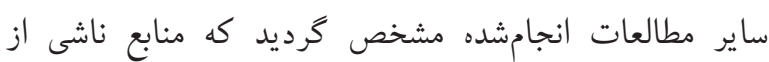

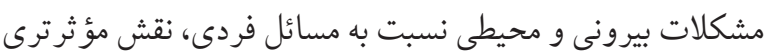

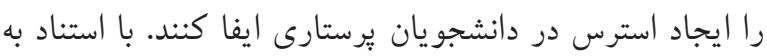
نتايج اين تحقيق مىتوان گفت كه بايد قدمهايى را در جهت

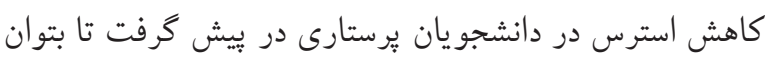

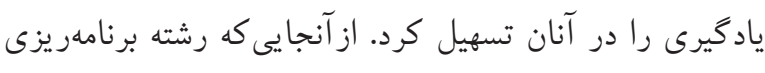

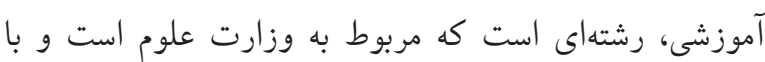
رشته يرستارى، كه جزو زيرشاخههاى علوم يزشكى و مربوط إنه

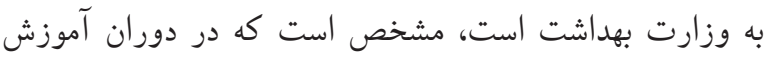
يرستارى (نظرى، عملى و كارورزى) از اصول و مبانى تعليم و

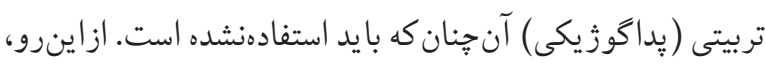

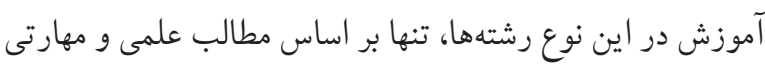

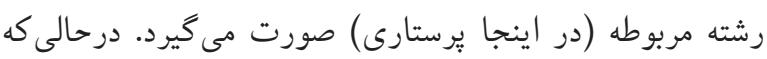

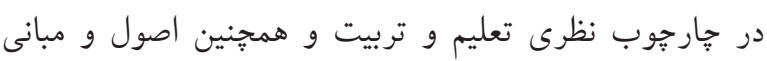

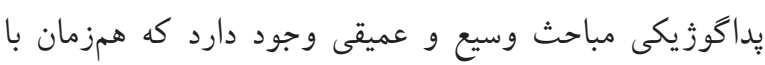

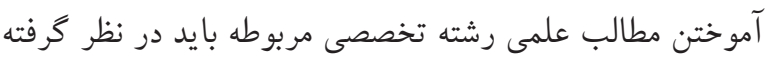

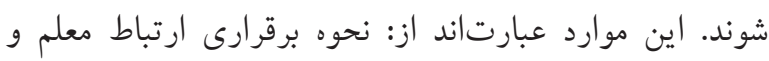

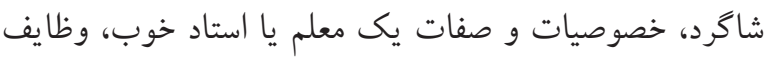
و توانايىهاى تعليم و تربيت معلم يا استاد نسبت به شاكرد و ورديات

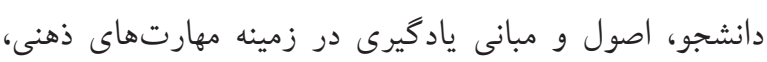

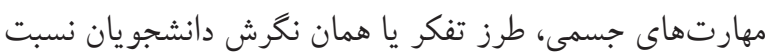

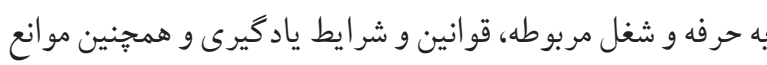

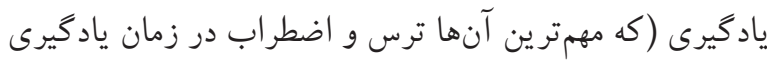

وضعيت آموزش و تسلط مربيان روبرو شدند. شايد استفاده از مربيان كمتجربه كه مهارت برقرارى ارتباط را بهخوبى نمىدانند

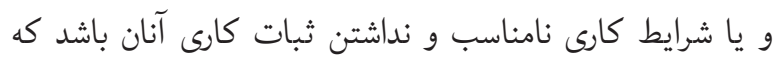
سبب عصبانيت و تشويش آنها مى گردد.

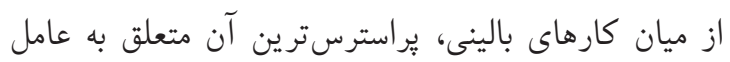

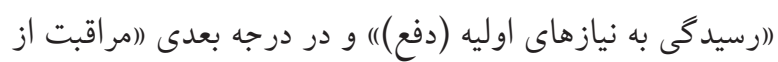

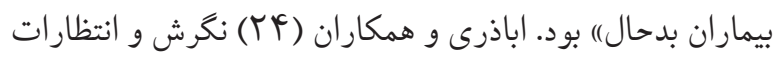

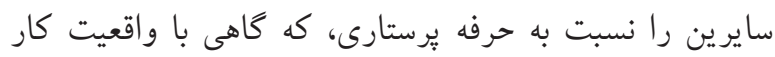

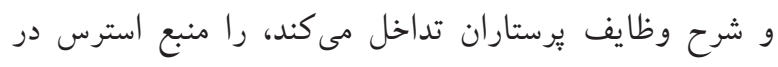

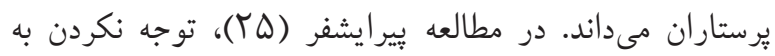

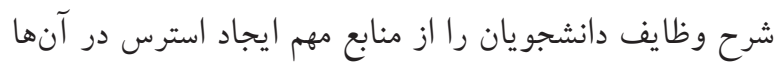
بيان كرده است. دانشجويان جوان در عرصه كار تيمى در بخشها

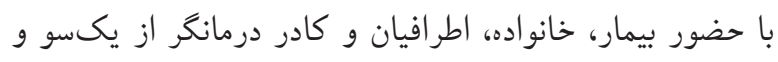
روحيه حساس و كمتجربكى از سوى ديكر دجار استرس مى بوند.

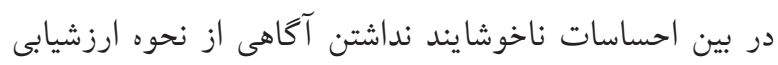
بالينى و يساز آن رنج كشيدن بيمار، مهمترين منابع استرسزا معرفى شدند. هاشمينظرى و همكاران (Y\&) مراقبت ناكافى دونى

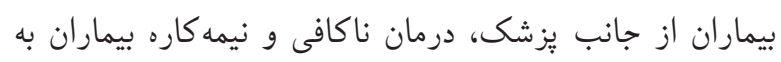

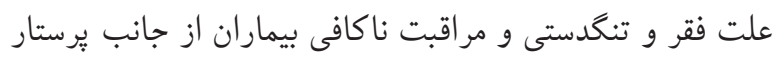
را مهمترين منابع استرس ذكر كردهاند. مطالعه آصفزاده (TV) آموزش يُشكى راد در تربيت يز شكان ماهر و متعهد ناكام دانسته

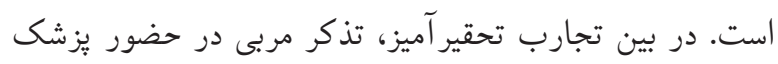

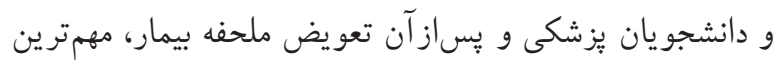

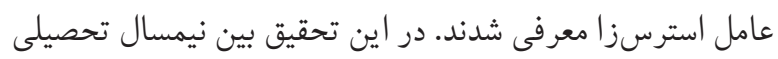
و استرسزا بودن كارهاى بالينى ازنظر دانشجويان همبستكى

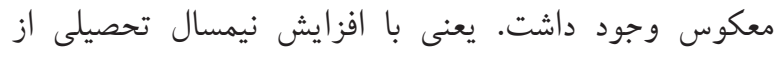

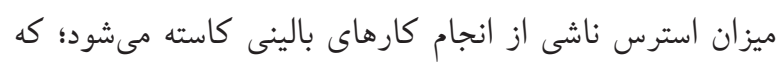
البته ازنظر آمارى رابطه معنادارى وجود نداشت نتايج مطالعات أنسات

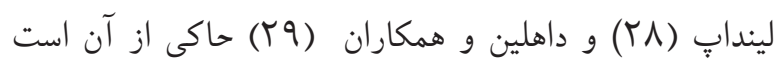
كه استرس با افزايش كار آزمودگى دانشجويان بيشتر شده است.

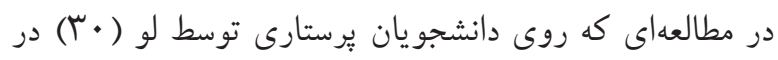


((تجربيات تحقيرآميز)) بيشترين عامل استرسزا متعلق به عامل ((تعويض ملحفه بيمار)) و كمترين آن متعلق به عامل (ركلايه كردن بيماران و همراهان در مورد رفتار نامناسب پيرستاران) بود. بين محل سكونت، وضعيت تأهل و دوره تحصيلى دانشجويان و ميزان استرسزا بودن عوامل كوناگون ارتباط معنادارى وجود نداشت. دانشجويانى كه در نيمسالهاى تحصيلى بالاتر بودند، استرس كمترى را در محيطهاى بالينى تجربه نمودند. روشهاى مقابله با استرس نشان داد كه اكثر ياسخدهندگان بيشتر تمايل به استفاده از راههاى هيجانمدار تا روشهاى مسئلهمدار براى مقابله با استرس داشتند. نتيجه اينكه تعدادى از دانشجويان يرستارى مشكوك به اختلالات روانى هستند. ازاينرو، بهمنظور جلو گيرى از اثرات تخريبى روانشناختى و جسمى ناشى از استرس بر دانشجويان، تأمل درباره عوامل استرسزاى آموزشى جهت كاهش مسائل ذهنى توصيه ميشود.

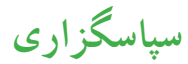
از كليه مسئولين دفتر يرستارى و سويروايزرهاى محترم آموزشى و همجنين مربيان و اساتيد محترم يرستارى بيمارستانهاى آموزشى تحت نظارت دانشگاه علوم يزشكى تهران كه براى به انجام رسانيدن اين يزوهش، همكارى نمودهاند، كمال تشكر ميشود.

\section{References}

1. Abdollahi,D. Development and Evolution management in Virtual Education: Developing a pedagogical infrastructure of Virtual Education. Department of Education, (2014); Osmania University, Hyderabad, India.

2. Abdollahi, D. Development and Evolution management in Virtual Education". Department of Education, (2014); Osmania University, Hyderabad, India.

3. Martin C. reducing distress in first level and student nurses: a review of the applied stress management literature. Journal of Advanced Nursing 2000; 32(1): 66-74.

4. Dahlin M, Joneborg N, Runeson B. Stress and depression among medical students: across-sectional study. Med Educ 2005; 39(6): 594-604.

5. Esfandiari Gh. [Barrasye avamele steresza dar beine daneshjooyane daneshgahe oloom pezeshkye Kordestan va rabeteye an ba salamate omoomye anan dar sale 1378]. Teb \& Tazkie. 2001; (43): 57-64. [Persian]

6. Hayati, F. Moghabeleh ba Stress dar Zanan ba Saratan
است). لذا ييشنهاد مىشود براى افر ادى كه بهعنوان مربيان بالينى يرستارى انتخاب مىشوند و امر خطير و حساس مربى گرى را در محيطهاى بالينى به عهدهدارند، دورههاى مربوط به روشها و و فنون تدريس، روانشناسى تربيتى، سنجش و اندازهيرى بيشرفت تحصيلى، ارتباط بين فردى و ميان فردى را بر گزار كنند. اين مباحث در كنار مباحث تخصصى رشته يرستارى مىتواند باعث شود كه در زمان تعليم و تربيت توسط مربيان و استادان، نكرش دانشجو يان يرستارى نسبت به حرفه خود مثبت شود.

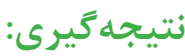
از عوامل استرسزاى مربوط به ((ارتباطات بين فردى))، بيشترين عامل استرسزا متعلق به عامل (ارتباط دانشجو با مربى)) و كمترين آن متعلق به عامل ((ارتباط با دانشجويان ديخر)) و ((بيمار)) بود. از عوامل استرسزاى مربوط به ((فعاليتهاى بالينى))، بيشترين عامل استرسزا متعلق به عامل (ارسيدگى به نيازهاى اوليه (دفع))، و كمترين آن متعلق به عامل ((دادن داروهاى خوراكى)" و ((دادن داروهاى غيرخوراكى)) بود. از عوامل استرسزاى مربوط به ((احساسات ناخوشايند))، بيشترين عامل استرسزا متعلق به عامل (اعدم آكاهى از نحوه ارزشيابى بالينى و كمترين آن متعلق به عامل) توجه ناكافى يرستار بود. از عوامل استرسزاى مربوط به

e Sineh Oud kardeh be bimarestanhay e vabasteh be Daneshgah e olum e pezeshki e Tehran. Majaleh Iranian e Bimarihay e Sineh 2008; 1 (2): 38-43. [Persian]

7. Kockly R. "Strees and fatigue in Mental Health Nursing" 5th Ed. Fontain Flettcher-Fondations Of NeurologyPearson Education 2003. [Persian]

8. Sadeghian, E. Et al. Avamel e Stressza va Ertebat An ba Salamt e Ravani e Daneshjoyan Daneshgah e Olum e Pezeshki e Hamedan 2013. [Persian]

9. Vaughans B. W. Nursing Fundamentals DeMYSTiFieD: A Self-Teaching Guide. New York: McGraw-Hill Education / Medical, 2010.

10. Delaram, M. Asarat e Raftar Darmani e Shenakhiti dar Mord e Strategyhay e Moghabelehei baray e Daneshjoyan e Ghair e Pezeshki Daneshgah e olum e Pezeshki e Shar e Kord 2003; 5(3): 26-34. [Persian]

11. Khodayarifard, M. et al. Stress va Rah haye Moghabeleh ba An. Entesharat e Daneshgah e Olum e Pezeshki e Tehran 2011. [Persian] 
12. Kamali, S. et al. Mental health and its relationship with stress coping strategies and emotional intelligence in female students at pre-university level. Journal of Behavioral Sciences, Vol.7, No.1,Spring 2013 Pages:49-56

13. Abdollahi, D. Philosophy and Goals \& Digital concepts as two Main Components in Virtual Higher Education". Department of Education, 2014, Osmania University, Hyderabad, India

14. Tehrani H, Rakhshani T, Zadeh DS, Hosseini SM. Analyzing the relationship between job stress to mental health, personality type and stressful life events of the nurses occupied in tehran 115 emergency. Iranian Red Crescent Medical Journal. 2013;15(3):272-3.

15. Saber M, Tehrani H, Shojaeizadeh D, Maleki Z, Esfandiyarpoor R. Mental Health and Exposure to Stressful Life Events of Nurses Working in Emergency Medical Service (ER 115). Journal Health System Research. 2013;9(3):294-300.

16. Mirzaei, O. Vaghei, S. Koshan, M. Tasir e Amoozesh e Maharathay e Ertebati bar Mizan e Stress Edrak Shodeh dar Daneshjouyan e Reshteh Parastari. Majaleh Daneshgah e Olum e Pezeshki va Khadamat e Darmani e Sabzevar 2010; 17 (95/2). [Persian]

17. Habibzadeh, S. Baresi Mizan e Oft e Tahsili va Avamel e Moaser bar An dar Daneshjoyan. Majaleh Salamat va Moraghebat 2011; 13th year, no 13. [Persian]

18. Abdollahi, D. The Role of Educational Planning in TeachingLearning Process Improvement of the Virtual Education Organization. Department of Education, 2014; Osmania University, Hyderabad, India.

19. Omidvar, sh. Bakoei, F. Salamlian, H. Barresi e Moshkelat e Amouzesh e Balini az Nazare Daneshjoyan e Saal e Akhar e Mamaei Daneshgah olom e pezeshki e Babol, Gozaresh Nahaei e Tarh e Tahghighati, Daneshgah e olom e pezeshki e Babol; pg 35. [Persian]

20. Saki M, Roohandeh M. [Barrasye avamele estereszaye amoozeshe balinye parastari az didgahe daneshjooyane parastari va rahkarhaye amali dar khosoose behboode keifiate amoozeshe balini]. Iranian Journal of Medical Sciences. 2005; 5 (14): 169. [Persian]

21. Karimi, Z. Mizan e Ezterab va Avamel e Mortabet ba An dar Mohit e Balini dar Daneshjoyan e Otagh e Amal va Hoshbari, Majaleh Irani e Amozesh e Pezeshki 2001; Vijehnameh 14. [in Persian]

22. Abazari, F. et al. Mizan e Stress va Avamel Stressza dar Daneshjoyan e Parastari. Gami dar Toseaye Pezeshki 2004. [Persian]

23. Khorsandi, M., Khosarvi, S. Baresi Vazeiyat e Amozesh e Balini az Didgah e Daneshjoyan e Parastari Mamaei Arak. Majaleh Rah Avard e Danesh 2001; 5 (1): 32. [Persian] http://fa.journals.sid.ir/ViewPaper.aspx?id=19870

24. Abazari F, Abaszadeh A, Arab M. [Barrasye miza $n$ va manabeae esteres dar daneshjooyane parastari]. Strides In Development of Medical Education. 2004; 1: 31. [Persian]

25. Pirayeshfar, A. Baresi e Elale Zaef e Ifay e Naghsh e Balini e Daneshjoyan e Parastari. Kholaseh Maghalat e Seminar e Sarasari Baresi Moshkelat Amoozesh e Balini e Parastari va Mamaei. 1992; 2-41.

26. Hashemi Nazari S, Khosravi J, Faghizadeh S, Etemadzadeh H. [Barrasye salamate ravane karkonane sazmane atashneshani ba estefade az porseshnameye salamate omoomye 28 soali dar sale 1384]. Hakim. 2007; 10(2): 5664. [Persian]

27. Asefzadeh, S. Amoozesh e Pezeshki va khadamat e darmani. Entesharat e Elmi va Farhangi 1996; pg 139. [Persian]

28. Lindop E. A comparative study of stress between pre and post-project 2000 students. J Adv Nurs 1999; 29(4): 96773.

29. Dahlin M, Joneborg N, Runeson B. Stress and depression among medical students: across-sectional study. Med Educ 2005; 39(6): 594-604.

30. Lo R. A. longitudinal study of perceived level of stress, coping and self esteem of undergraduate nursing students: An Australian case study. J Adv Nurs 2002; 39(2): 119-26. 